Report

\title{
Osteopontin(OPN)-induced increase in human mammary epithelial cell invasiveness is urokinase (uPA)-dependent
}

\author{
Alan B. Tuck ${ }^{1,2,3,4}$, Charulata Hota ${ }^{1,2,3,4}$, and Ann F. Chambers ${ }^{1,2,4}$ \\ Departments of ${ }^{1}$ Pathology and ${ }^{2}$ Oncology, University of Western Ontario; ${ }^{3}$ London Health Sciences Centre; \\ ${ }^{4}$ London Regional Cancer Centre, London, Ontario, Canada
}

Key words: breast cancer, cell invasion, mammary epithelial cells, osteopontin (OPN), urokinase (uPA)

\begin{abstract}
Summary
We have recently shown that either exogenous or endogenous, transfected OPN induces both uPA expression and increased invasiveness of 21PT (non-tumorigenic) and 21NT (tumorigenic) human mammary epithelial cells. Here we asked whether uPA contributes functionally to the increased invasiveness of these cells. The most invasive OPN-transfected cells were assessed for migration through Matrigel in transwell assays, in the presence or absence of various blocking antibodies and uPA inhibitors. Antibodies to both uPA and uPA receptor (uPAR) were shown to significantly inhibit cell invasion, as did the uPA inhibitors (plasminogen activator inhibitor-1 [PAI-1], paminobenzamidine [PABN], aprotinin, and amiloride). Both anti-uPA and anti-uPAR antibodies inhibited invasion to a level comparable to that of the control vector transfected cells. In contrast, non-specific IgG showed no antiinvasive effect. Cell migration experiments performed with the parental cell lines in the presence or absence of anti-uPA or anti-uPAR antibodies showed that uPA is also required for migratory responsiveness to exogenous OPN. These data thus provide direct evidence that OPN-induced invasion and migration of these cells requires uPA.
\end{abstract}

\section{Introduction}

Osteopontin (OPN) is a secreted, integrin-binding glycophosphoprotein which has been associated with malignancy of breast cancer and other tumors. Our clinical studies have shown an association between level of OPN in the primary tumor [1] or blood [2] and outcome in patients with breast cancer. In cell culture experiments, we have recently shown that either exogenous, or endogenous, transfected OPN induces both urokinase-type plasminogen activator (uPA) expression and increased invasiveness of 21PT (non-tumorigenic) and 21NT (tumorigenic) human mammary epithelial cells [3].

uPA is a serine protease, which when bound to its cell surface receptor, urokinase-type plasminogen activator receptor (UPAR), is capable of activating a variety of other proteases (either directly or indirectly by activating plasminogen) (e.g., pro-MMP-1, -2, -3, $-9,-14)$ [4-6]. This, in turn, results in digestion of various components of the ECM (reviewed in [6]), as well as activation of certain growth factors (reviewed in $[6,7])$. uPA expression and activity has been associated with invasiveness of a variety of cancer cell lines, and clinically with poor prognosis of patients with breast cancer and other malignancies (reviewed in [7]).

Here we have asked whether uPA contributes functionally to the invasiveness of mammary epithelial cells transfected to overexpress OPN. OPNtransfected $21 \mathrm{~T}$ series cells were tested in invasion assays performed in the presence or absence of either blocking antibodies (to UPA or UPAR), or natural or chemical inhibitors of urokinase, in order to determine whether uPA/uPAR is necessary for their invasiveness. We found that anti-uPA and uPAR antibodies and uPA inhibitors all effectively blocked invasiveness of the OPN transfectants. As others have shown that integrinmediated cell migration of different mammary epithelial cell lines may be uPA dependent [8, 9], we also examined the effect of anti-uPA and uPAR antibodies on responsiveness of the parental (non- 
transfected) 21PT and 21NT cell lines to exogenous OPN in cell migration assays. We found that both antibodies inhibited OPN-induced cell migration as well, indicating that a component of the uPA-dependency of OPN-induced cell invasion in these cells is due to effect on cell migration.

\section{Materials and methods}

\section{Cell lines and culture}

The 21T series cell lines (21PT, 21NT) were obtained as a kind gift of Dr. Vimla Band (Dana Farber Cancer Institute) [10]. Osteopontin and control vector (pcDNA3) transfectants of these cell lines were as described previously [3]. Transfectant cell lines are defined as follows: PT/Ci and NT/Ci: pooled populations of 21PT (non-tumorigenic) and 21NT (tumorigenic, non-metastatic) cells transfected with the neo-containing control vector (pcDNA3) only, PT/OPaiiPool and PT/OPaiiC12: pooled and cloned population (respectively) of OPN-transfected 21PT cells expressing the highest levels of OPN, NT/OPbiPool and NT/OPaiiC4: pooled and cloned population (respectively) of OPN-transfected 21NT cells expressing the highest levels of OPN [3]. The transfectant cell lines were maintained in culture in $\alpha$-MEM supplemented with $10 \%$ FCS, $2 \mathrm{mM} \mathrm{L-}$ glutamine (all from GIBCO-BRL/Life Technologies, Grand Island, NY), insulin $(1 \mu \mathrm{g} / \mathrm{ml})$, epidermal growth factor [EGF] $(12.5 \mathrm{ng} / \mathrm{ml})$, hydrocortisone $(2.8 \mu \mathrm{M}), 10 \mathrm{mM}$ HEPES, $1 \mathrm{mM}$ sodium pyruvate, $0.1 \mathrm{mM}$ nonessential amino acids, and $50 \mu \mathrm{g} / \mathrm{ml}$ gentamycin (all from Sigma Chemical, St. Louis, MO) ( $\alpha \mathrm{HE}$ medium), and G418 (200 $\mu \mathrm{g} / \mathrm{ml}$ [active], GIBCO-BRL/Life Technologies).

\section{RNA isolation and northern blot analysis}

Cell pellets from subconfluent monolayers were mechanically homogenized (Polytron PT 1200, Brinkman Instruments [Canada] Ltd., Mississauga, ON) and RNA extracted using TRIzol Reagent (Canadian Life Technologies Inc., Burlington, ON), according to the protocol supplied by the manufacturer. RNA $(10 \mu \mathrm{g} /$ lane) was run on a $1.1 \%$ agarose gel with $6.8 \%$ formaldehyde, and capillary-transferred to GeneScreen Plus filters (DuPont Canada Inc., Mississauga, ON). Blots were probed either with denatured, oligolabeled $\left[{ }^{32} \mathrm{P}\right]$-dCTP cDNA probes (labeled using a kit provided by Pharmacia, Baie d'Urfe, PQ), or with $5^{\prime}\left[\gamma^{32} \mathrm{P}\right]$-ATP end-labeled oligomers (labeled using a kit provided by Oncogene Science, Manhasset NY), according to the procedures provided by the manufacturers, and as previously described $[11,12]$.

The OPN probe used was the full-length (1493 bp) human OPN cDNA EcoRI cassette of plasmid OP-10 [13]. The probe for human urokinase-type plasminogen activator was a 40mer antisense oligonucleotide derived from the translated sequences of exon 4 (Calbiochem/Cederlane Laboratories, Hornby, Ontario, Cat\#ON333) [14]. The urokinase-type plasminogen activator receptor probe was a $45 \mathrm{mer}$ antisense oligonucleotide to the first 15 amino acids (not including the signal peptide) [15]. Even loading of lanes was confirmed by probing blots with a human $18 \mathrm{~S}$ rRNA probe (p100D9, a kind gift from Dr. D.T. Denhardt).

\section{Enzymogram analysis of UPA in conditioned medium}

Conditioned media were prepared by plating cells at $5 \times 10^{5}$ cells $/ 100 \mathrm{~mm}$ plate in regular growth medium and incubating overnight $(18 \mathrm{~h})$ at $37^{\circ} \mathrm{C}, 5 \%$ $\mathrm{CO}_{2}$. Medium was then removed, and plates were washed X1 with warm, sterile PBS, and X2 with serum-free OPTI-MEM (GIBCO-BRL/Life Technologies). Serum-free OPTI-MEM was then added at $3 \mathrm{mls} / 100 \mathrm{~mm}$ plate, and plates were incubated for $48 \mathrm{~h}$ at $37^{\circ} \mathrm{C}, 5 \% \mathrm{CO}_{2}$. Following the incubation period, the conditioned medium from each plate was collected, and the cell debris spun out. The corresponding plate was trypsinized, and a cell count performed, to allow appropriate correction in loading for cell equivalents.

Aliquots of conditioned medium were adjusted for cell number and diluted 1/50 for enzymogram analysis. The samples were separated by $11 \%$ SDSPAGE, the gel impregnated with $0.1 \%$ casein and $10 \mu \mathrm{g} / \mathrm{ml}$ plasminogen as previously described [16]. The gel was then incubated in $2.5 \%$ Triton-X 100 for $2 \mathrm{~h}$, followed by incubation in $50 \mathrm{mM}$ Tris $(\mathrm{pH} \mathrm{8.3)}$ and $0.1 \mathrm{M}$ glycine for $18 \mathrm{~h}$ at $37^{\circ} \mathrm{C}$. The gel was fixed in $15 \%$ acetic acid and stained with $0.25 \%$ Coomassie blue. Following destaining, plasminogen-dependent proteolysis was detected as a white band on a dark background.

\section{Cell invasion assay}

In vitro invasiveness through Matrigel was assayed as described previously [12], using 24-well transwell 
chambers with polycarbonate filters of $8 \mu \mathrm{m}$ pore size (Costar, Cambridge, MA), coated with $35 \mu \mathrm{g}$ Matrigel (Collaborative Research Inc., Bedford, MA) containing $50 \mu \mathrm{g} / \mathrm{ml}$ plasminogen (Sigma). The Matrigel concentration was determined by preliminary experiments using representative OPN-transfected $21 \mathrm{~T}$ series cell lines. Matrigel was diluted to the desired final concentration with cold, sterile, distilled water, applied to the filters, dried overnight in a tissue culture hood, and reconstituted the following morning with serum-free $\alpha \mathrm{HE}$ medium. Cells for the assay were trypsinized and seeded to the upper chamber at $5 \times 10^{4}$ cells per well in serum-free $\alpha \mathrm{HE}$ medium containing $0.1 \%$ BSA, with or without the specified antibody or inhibitor. Studies examining the effects of blocking antibodies used $200 \mu \mathrm{g} / \mathrm{ml}$ mouse antihuman uPA (American Diagnostica, Montreal, Quebec, Canada), $200 \mu \mathrm{g} / \mathrm{ml}$ mouse anti-human uPAR (American Diagnostica), or $200 \mu \mathrm{g} / \mathrm{ml}$ non-specific mouse IgG (Cedarlane). Studies examining the effects of uPA inhibitors used $50 \mu \mathrm{g} / \mathrm{ml}$ human recombinant plasminogen activator inhibitor-1 (PAI-1) (American Diagnostica), $2 \mathrm{mM}$ p-amino-benzamidine (Sigma), $200 \mu \mathrm{g} / \mathrm{ml}$ aprotinin (Sigma), or $200 \mu \mathrm{M}$ amiloride (Sigma). The concentration of inhibitor used was determined by preliminary experiments to achieve maximum effect with minimal toxicity ( $>90 \%$ cell survival in viability assay). The lower chamber was filled with serum-free culture medium with $0.1 \%$ BSA and $10 \mu \mathrm{g} / \mathrm{ml}$ fibronectin. Plates were incubated for $72 \mathrm{~h}$ in a $5 \% \mathrm{CO}_{2}$ incubator at $37^{\circ} \mathrm{C}$. Following incubation, the upper wells were removed, fixed with $1 \%$ glutaraldehyde in phosphate-buffered saline, stained with hematoxylin, dipped briefly in $1 \%$ ammonium hydroxide, and washed with water. The cells and Matrigel were then wiped off the upper surface of each filter with a cotton swab. After air-drying, cells from various areas of the lower surface of the filters were counted under $\times 100$ magnification.

\section{Cell migration assay}

Cell migration assays were performed essentially as described previously [17], using 24-well transwell chambers with polycarbonate filters of $8 \mu \mathrm{m}$ pore size (Costar). Gelatin (Sigma) was applied at $6 \mu \mathrm{g} /$ filter and air dried. The gelatin was rehydrated with $100 \mu 1$ of serum-free $\alpha \mathrm{HE}$ medium at room temperature for $90 \mathrm{~min}$. Lower wells contained $600 \mu \mathrm{l}$ of $\alpha \mathrm{HE}$ plus $0.1 \%$ BSA, with or without human recombinant OPN $(50 \mu \mathrm{g} / \mathrm{ml})$ [18]. Previous control experiments have shown that the GST portion alone has no influence on migration of these cells. Cells $\left(5 \times 10^{4}\right)$ were added to each upper well in $\alpha \mathrm{HE}$ medium with $0.1 \% \mathrm{BSA}$ and incubated for $5 \mathrm{~h}$ at $37^{\circ} \mathrm{C}$. At the end of the incubation time, the cells that had migrated to the undersurface of the filters were fixed in place with gluteraldehyde and stained with hematoxylin. Cells that had not migrated and were attached to the upper surface of the filters were removed from the filters with a cotton swab. The lower surfaces of the filters were examined microscopically under $100 \times$ magnification and representative areas were counted to determine the number of cells that had migrated through the filters. For experiments with blocking antibodies, cells were pre-incubated for $20 \mathrm{~min}$ at room temperature with medium containing either $200 \mu \mathrm{g} / \mathrm{ml}$ mouse anti-human uPA (American Diagnostica) or $200 \mu \mathrm{g} / \mathrm{ml}$ anti-uPAR (American Diagnostica).

All cell migration and invasion assays were performed in triplicate. Statistical differences between groups were assessed using Student's $t$-test, with SigmaStat (Jandel Scientific, San Rafael, CA) statistical software.

\section{Results}

Relative levels of OPN mRNA and protein (as determined by northern and western analysis respectively) expressed by OPN versus control vector transfectants of 21PT and 21NT cells are shown in Table 1. Both OPN transfected 21PT (PT/OPaiiPool, PT/OPaiiC12) and 21NT (NT/OPbiPool, NT/OPaiiC4) cells showed increased invasiveness through Matrigel compared to controls (PT/Ci, NT/Ci), in proportion to their respective level of OPN expression (Table 1). Northern analysis (Figure 1(a)) further indicated that although uPAR mRNA levels did not show significant differences between the cell lines, uPA mRNA expression was closely related to the level of OPN expression, and cellular invasiveness (cf Table 1). Similarly, enzymogram analysis of conditioned media showed the same rank order of the cells, with the highest uPA activity detected in the highest OPN-expressing cells (Figure 1(b), Table 1). Hence, OPN expression was found to be tightly correlated with cellular invasiveness and uPA expression and activity.

We then examined the uPA-dependency of OPNinduced cell invasiveness, focusing initially on the 21NT-derived OPN-transfected cell lines. Invasion through Matrigel of both NT/OPbiPool and 
Table 1. Osteopontin expression, urokinase activity and cellular invasion through Matrigel (35 $\mu \mathrm{g})$ in transwell assay for control (Ci) and osteopontin (OP) transfected 21PT (PT) and 21NT (NT) cells

\begin{tabular}{lccll}
\hline Cell line* & $\begin{array}{l}\text { Relative level of } \\
\text { OPN mRNA by } \\
\text { northern } \\
\text { analysis }\end{array}$ & $\begin{array}{l}\text { Relative level of } \\
\text { OPN protein by } \\
\text { western analysis } \\
\text { of conditioned } \\
\text { media }\end{array}$ & $\begin{array}{l}\text { uPA activity of } \\
\text { conditioned } \\
\text { media by } \\
\text { densitometry of } \\
\text { enzymogram }\end{array}$ & $\begin{array}{l}\text { Invasion through Matrigel } \\
\text { (cells/hpf }+/- \text { S.E) }\end{array}$ \\
\hline PT/Ci & 1.0 & 1.0 & $1.9+/-0.09$ & $5.42+/-1.34$ \\
PT/OPaii Pool & 10.9 & 5.3 & $2.9+/-0.07$ & $38.25+/-4.63$ \\
PT/OPaiiC12 & 35.5 & 10.1 & $3.7+/-0.08$ & $56.15+/-4.63$ \\
NT/Ci & 3.5 & 1.1 & $2.2+/-0.01$ & $14.83+/-0.79$ \\
NT/OPbi Pool & 28.4 & 4.6 & $3.6+/-0.03$ & $44.80+/-1.83$ \\
NT/OPaiiC4 & 34.9 & 8.0 & $4.7+/-0.16$ & $63.67+/-1.86$ \\
\hline
\end{tabular}

* Key to cell lines: PT/Ci: pooled population of 21PT cells transfected with the control vector (pcDNA3) only; PT/OPaiiPool: pooled population of 21PT cells transfected with the OPN-expression vector (pool expressing highest level of OPN protein); PT/OPaiiC12: clone 12 of OPN-transfected 21PT pool aii (clone expressing highest level of OPN protein); NT/Ci: pooled population of 21NT cells transfected with the control vector (pcDNA3) only; NT/OPbiPool: pooled population of 21NT cells transfected with the OPNexpression vector (pool expressing highest level of OPN protein); NT/OPaiiC4: clone 4 of OPN-transfected 21NT pool aii (clone expressing highest level of OPN protein). All cells as obtained in reference [3].

NT/OPaiiC4 cells was markedly inhibited (to control NT/Ci transfectant levels) by both anti-uPA and antiuPAR antibodies, as well as by the natural plasminogen activator inhibitor, PAI-1 (Figure 2). In contrast, no blocking effect was seen with the non-specific IgG (Figure 2). Incubation of the cells in the presence of several chemical inhibitors of uPA activity (p-aminobenzamidine, amiloride, aprotinin) also showed significant inhibition of both OPN-transfected 21NT cell lines (Figure 3). In the case of p-amino-benzamidine and amiloride, inhibition of cell migration was seen to levels below that of the control transfectant (NT/Ci) cell line, whereas that achieved with aprotinin was to levels approximating that of the control. The OPN-transfected 21PT cell lines (PT/OPaiiPool and PT/OPaiiC12) were also tested, and showed the same pattern of inhibition by anti-uPA and anti-uPAR antibodies, by PAI-1, and by the chemical inhibitors p-amino-benzamidine, amiloride and aprotinin (data not shown).

In order to assess whether cell migration responsiveness to uPA/uPAR is a component of cell invasiveness induced by OPN, we also examined the ability of anti-uPA and anti-uPAR antibody to block OPN-induced cell migration of the parental (nontransfected) 21PT and 21NT cell lines (Figure 4). Both cell lines showed significant inhibition (to levels around or below baseline) of OPN-induced cell migration with either anti-uPA or anti-uPAR antibody treatment.

\section{Discussion}

Several clinical studies have indicated a worse prognosis of breast cancer in patients showing elevated expression of either OPN $[1,2]$ or uPA (review in [7]). One recent study provides evidence that breast cancers metastatic to bone have a tendency to overexpress both OPN and UPA, raising the possiblity that these proteins interact to contribute to metastasis [19]. Work by ourselves and others have shown that high level expression of OPN by mammary epithelial cells is associated with increased malignancy in terms of cell migration $[3,17,20-22]$, invasion $[3,23]$ and metastatic ability $[24,25]$. Recently, we have further shown that a component of the cellular response to OPN is upregulation of uPA expression [3]. In the present study, we have examined specifically whether the UPA/UPAR axis is functionally required for the OPN-induced increase in cellular invasiveness of 21T series mammary epithelial cells. Through antibody blocking and inhibitor experiments, we have shown that OPN-induced invasiveness of these cells is indeed dependent upon uPA/uPAR. In parallel studies with MDA-MB-435 cells, which show an inherent high level expression of OPN, we have seen the same inhibition of cell invasiveness with blocking anti-uPA and anti-uPAR antibodies and uPA inhibitors (Tuck and Chambers, unpublished observations). In addition, using 21PT and 21NT cells, we have found that a component of the uPA/uPAR dependency involves 
(a)

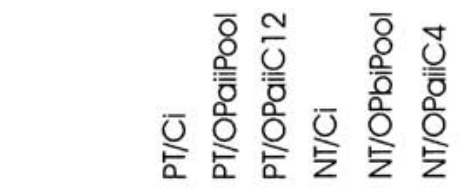

$2.3 \mathrm{~kb}$ -

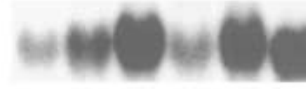

$1.4 \mathrm{~kb}$.

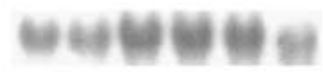

$2.1 \mathrm{~kb}$ -

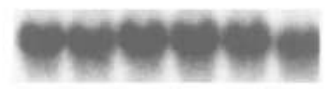

UPAR

18S IRNA

(b)

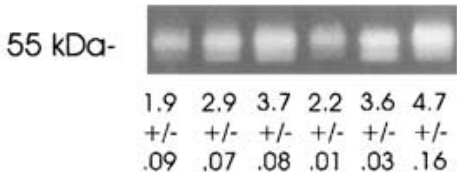

UPA

$\begin{array}{llllllll}0 & +/- & +/- & +/- & +/- & +/- & +/-\end{array}$

Figure 1. uPA and uPAR mRNA expression (a) and uPA protease activity (b) of control and OPN-transfectant cell lines. Vector-only transfected controls of 21PT (PT/Ci) and 21NT (NT/Ci) cells are compared with the OPN-transfected pool and clone of 21PT (PT/OPaiiPool; PT/OPaiiC12) and 21NT (NT/OPbiPool; NT/OPaiiC4) cells that expressed the highest levels of OPN. (a) Northern analysis for expression of uPA and uPAR mRNA. Probes were: human urokinase-type plasminogen activator (uPA); urokinase-type plasminogen activator receptor (uPAR); and 18S ribosomal RNA (18S rRNA). (b) Enzymogram assay for uPA protease activity in conditioned media. Enzymogram analysis of conditioned media was performed as described in Materials and methods. Plasminogen-dependent proteolysis is seen as a white band on a dark background. The band is of the expected MW of uPA (55 kDA). Below each band is shown the relative intensity, as determined by densitometry, plus or minus standard deviation on triplicate measurements. All OPN-transfected cell lines were found to exhibit increased amounts of uPA mRNA and enzyme activity relative to the vector-only transfected controls.

cell migration, as blocking antibodies show significant inhibitory effect even in the absence of a basement membrane barrier.

OPN has been shown to bind to the cell surface via a number of different receptors, both integrin $[17,18,21,26-30]$, and non-integrin (i.e., CD44 [31-33]). In 21T mammary epithelial cells, we have found integrins $\alpha \mathrm{v} \beta 55$ and $\beta 1$ of particular importance in the cell migration response to OPN [21]. The observation here that this cell migration is also dependent upon uPA/uPAR, suggests the possibility of interaction between activated cell surface integrins and UPA/uPAR for induction of migration by OPN. Consistent with these findings, a collaborative interaction between vitronectin-activated $\alpha v \beta 5$ integrin and uPA-bound UPAR has been reported in induction of migration in other systems $[8,9]$.

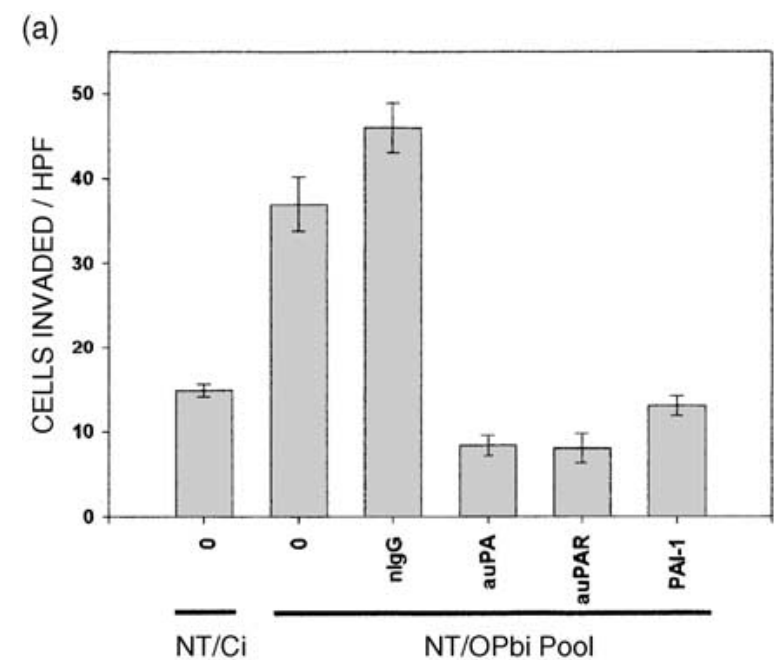

(b)

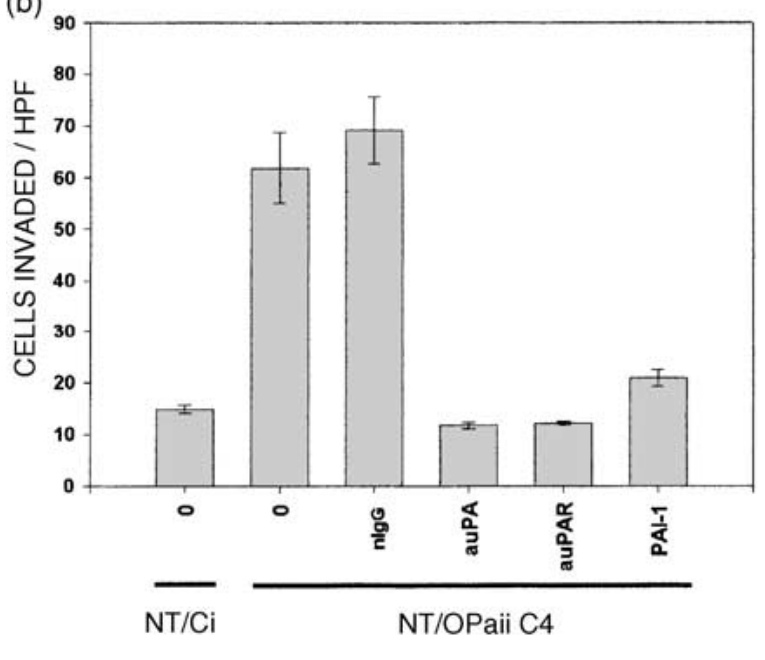

CELL TYPE AND TREATMENT

Figure 2. Anti-uPA, anti-uPAR and PAI-1 blocking of NT/OPbiPool (a) and NT/OPaii C4 cell (b) chemoinvasiveness, in comparison with basal level invasiveness of control vector transfectant $(\mathrm{NT} / \mathrm{Ci})$. Invasion was assessed in transwells in response to $10 \mu \mathrm{g} / \mathrm{ml}$ fibronectin in the lower chamber, through $8 \mu \mathrm{m}$ pore filters precoated with $35 \mu \mathrm{g}$ Matrigel, as described in Materials and methods. $5 \times 10^{4}$ cells/well were seeded to the upper chamber in $\alpha \mathrm{HE}$ medium $+0.1 \%$ BSA with: $0=$ no antibody; $\mathrm{nIgG}=200 \mu \mathrm{g} / \mathrm{ml}$ nonimmune mouse $\mathrm{IgG} ; \quad \operatorname{auPA}=200 \mu \mathrm{g} / \mathrm{ml}$ mouse anti-human uPA antibody; auPAR $=200 \mu \mathrm{g} / \mathrm{ml}$ mouse anti-human uPAR antibody; PAI- $1=60 \mu \mathrm{g} / \mathrm{ml}$ human recombinant plasminogen activator inhibitor-1. Bars represent the mean of counts from each of three separate wells, error bars are SEM. Anti-uPA and anti-uPAR antibodies showed marked inhibition of invasiveness of both NT/OPbi Pool and NT/OPaii C4 cells $(p=0.001$ for anti-uPA and anti-uPAR antibody inhibition of NT/OPbiPool; $p=0.0019$ for anti-uPA and anti-uPAR antibody inhibition of NT/OPaii C4 by Student's $t$-test), whereas no significant inhibition was seen with nonimmune mouse IgG. Significant inhibition of invasiveness of both NT/OPbiPool and NT/OPaii C4 cells was also seen with PAI- $1(p<0.001$ by Student's $t$-test). 
An influence on cell migration thus may be one component of the uPA effect on cell invasiveness induced by OPN. In addition, the uPA/uPAR axis is known to induce a cascade of protease activation
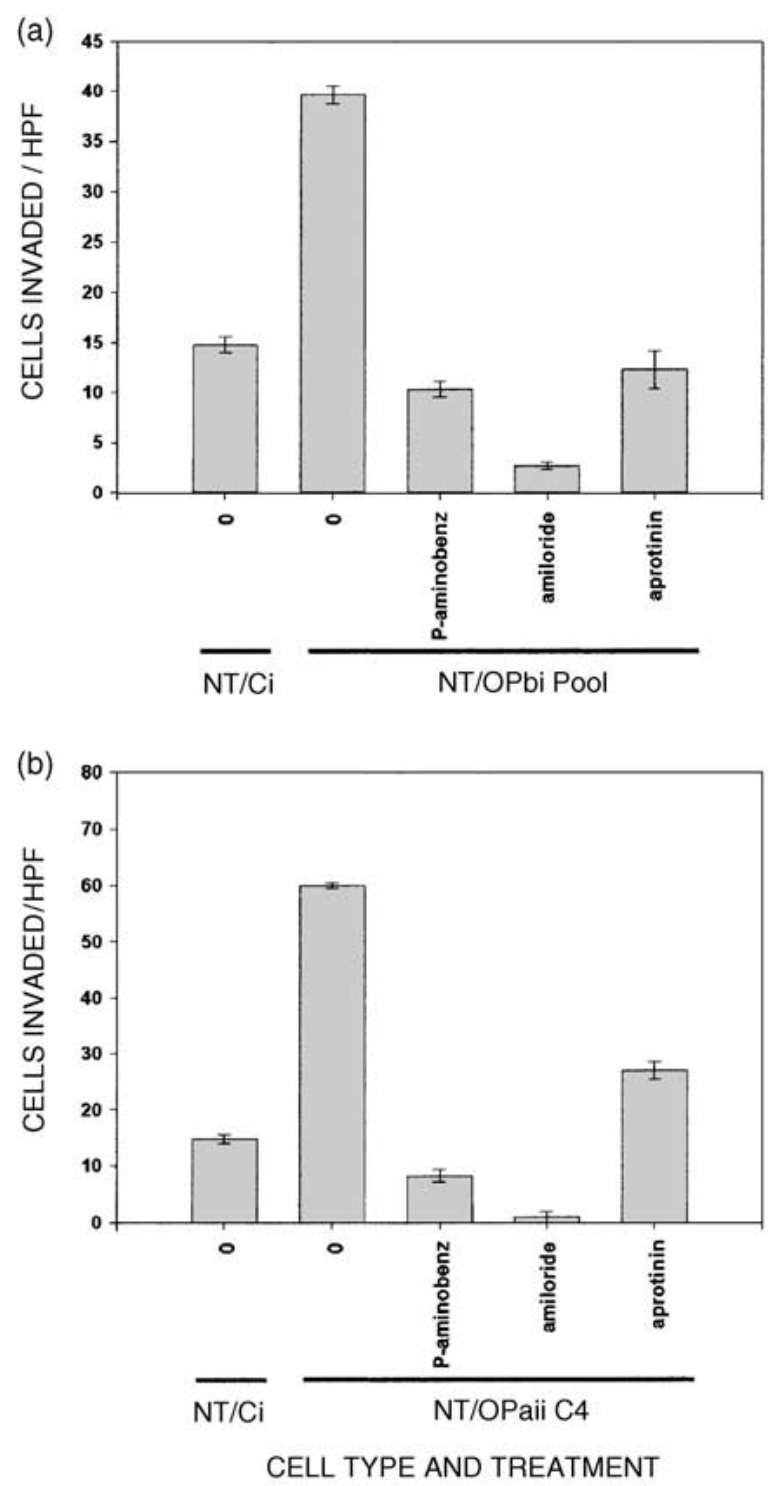

Figure 3. Inhibition of NT/OPbiPool (a) and NT/OPaii C4 cell (b) invasiveness by chemical inhibitors of uPA, in comparison with basal level invasiveness of control vector transfectant (NT/Ci). Transwell invasion assays were performed as described in Materials and methods and Figure 2, with experimental conditions as follows: $0=$ no inhibitor; P-aminobenz $=2 \mathrm{mM}$ p-amino-benzamidine; amiloride $=200 \mu \mathrm{M}$ amiloride , aprotinin $=200 \mu \mathrm{g} / \mathrm{ml}$ aprotinin. Bars represent the mean of counts from each of three separate wells, error bars are SEM. Significant inhibition of cellular invasiveness was seen with all four inhibitors $(p<0.001$ for all inhibitors, both cell lines, by Student's $t$-test).

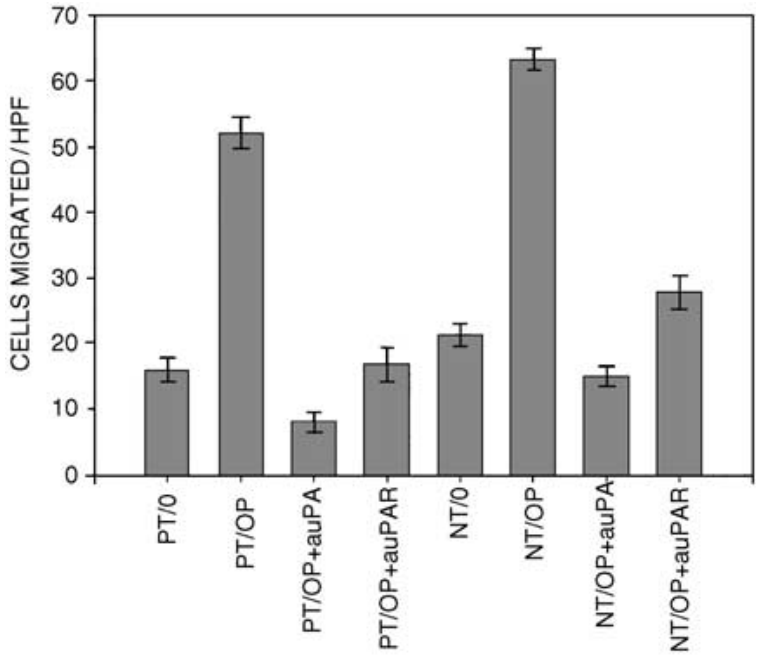

CELL TYPE AND TREATMENT

Figure 4. Anti-uPA and anti-uPAR antibody blocking of parental 21PT and 21NT cell migration response to exogenous (human recombinant) OPN. Cell migration assays were performed in transwells, as described in Materials and methods, using $50 \mu \mathrm{g} / \mathrm{ml}$ human recombinant $\mathrm{OPN}$ as the chemoattractant. Experimental conditions were as follows: PT $/ 0=21 \mathrm{PT}$ cells with no OPN in lower chamber, no inhibitory antibody; $\mathrm{PT} / \mathrm{OP}=21 \mathrm{PT}$ cells with $\mathrm{OPN}$ in lower chamber, no inhibitory antibody; PT/OP + auPA $=21 \mathrm{PT}$ cells with OPN in lower chamber, incubated with $200 \mu \mathrm{g} / \mathrm{ml}$ mouse anti-human uPA; PT/OP + auPAR $=21 \mathrm{PT}$ cells with $\mathrm{OPN}$ in lower chamber, incubated with $200 \mu \mathrm{g} / \mathrm{ml}$ mouse anti-human uPAR; $\mathrm{NT} / 0=21 \mathrm{NT}$ cells with no OPN in lower chamber, no inhibitory antibody; NT/OP $=21 \mathrm{NT}$ cells with $\mathrm{OPN}$ in lower chamber, no inhibitory antibody; NT/OP + auPA $=21 \mathrm{NT}$ cells with $\mathrm{OPN}$ in lower chamber, incubated with $200 \mu \mathrm{g} / \mathrm{ml}$ mouse anti-human uPA; NT/OP + auPAR $=21 \mathrm{NT}$ cells with OPN in lower chamber, incubated with $200 \mu \mathrm{g} / \mathrm{ml}$ mouse anti-human uPAR. Bars represent the mean of counts from each of three separate wells, error bars are SEM. Anti-uPA and anti-uPAR antibodies showed marked inhibition of both 21PT and 21NT cell migration ( $p<0.001$ for both antibodies, with both cell lines, by Student's $t$-test).

events which may either directly (by creating spaces through which invading cells may move) or indirectly (by modifying the nature of interactions with extracellular matrix components or growth factors) enhance invasion [4-7]. Thus, in activating uPA, OPN may not only start up the engine needed to drive cell movement, but also the system needed to create the spaces through which to move, and appropriately modify the environment to promote invasion.

The mechanism by which OPN binding to the cell surface results in activation of uPA expression and activity is at present unknown. However, one can postulate that this process may involve the activation of the hepatocyte growth factor (HGF) receptor, Met. Numerous studies with a number of different cell types 
have found previously that HGF treatment of cells activates expression of uPA [34-36], which in turn can activate HGF itself [37]. In 21T series cells, we have found that incubation with OPN results in increased expression and tyrosine kinase activity of Met [21], thus providing a potential pathway for uPA activation. If HGF/Met is indeed involved in UPA activation induced by OPN, this may offer a potential therapeutic target to block the effects of OPN in malignancy, in that potent inhibitors of the HGF/Met/uPA system have recently been identified [38].

In conclusion, the finding that cellular invasiveness and migration induced by OPN are dependent upon activation of uPA, provides functional evidence linking a number of studies to date which indicate the significance of both OPN and UPA in clinical and in vitro aggressiveness of breast cancer. Furthermore, the fact that UPA activation is functionally required for OPNinduced malignancy also has implications in choice of potential therapeutic targets, as effective strategies are in development for inhibiting pathways specifically involving uPA. Use of these uPA pathway inhibitors thus may be one effective approach to interfering with the malignancy-promoting effects of OPN.

\section{Acknowledgements}

The authors wish to acknowledge Kris Milne for technical assistance with computer graphics. Thanks also to Sylvia Hill for help in preparation of the human recombinant osteopontin used in migration assay experiments. This work was supported by grants from the Canadian Breast Cancer Research Initiative (\#12078) and the Breast Cancer Society of Canada. Dr. Tuck was supported by a 'Career Development' Award from the US Army Breast Cancer Research Program (D.O.D. DAMD17-96-1-6075). The content of this article does not necessarily reflect the position or policy of the US government, and no official endorsement should be inferred.

\section{References}

1. Tuck AB, O'Malley FP, Singal H, Harris JF, Tonkin KS, Kerkvliet N, Saad Z, Doig G, Chambers AF: Osteopontin expression in a group of lymph node negative breast cancer patients. Int J Cancer 79: 502-508, 1998

2. Singhal H, Bautista DS, Tonkin KS, O'Malley FP, Tuck AB, Chambers AF, Harris JF: Elevated plasma osteopontin in metastatic breast cancer associated with increased tumor burden and decreased survival. Clin Cancer Res 3: 605-611, 1997
3. Tuck AB, Arsenault DM, O'Malley FP, Hota C, Ling MC, Wilson SM, Chambers AF: Osteopontin induces increased invasiveness and plasminogen activator expression of human mammary epithelial cells. Oncogene 18: 4237-4246, 1999

4. Baricos WH, Cortez SL, el-Dahr SS, Schnaper HW: ECM degradation by cultured human mesangial cells is mediated by a PA/plasmin/MMP-2 cascade. Kidney Int 47: 1039-1047, 1995

5. Mazzieri R, Masiero L, Zanetta L, Monea S, Onisto M, Garbisa S, Mignatti P: Control of type IV collagenase activity by components of the urokinase-plasmin system: a regulatory mechanism with cell-bound reactants. EMBO J 16: 2319-2332, 1997

6. Werb Z: ECM and cell surface proteolysis: regulating cellular ecology. Cell 91: 439-442, 1997

7. Andreasen P-A, Kjøller L, Christensen L, Duffy MJ: The urokinase-type plasminogen activator system in cancer metastasis: a review. Int J Cancer 72: 1-22, 1997

8. Yebra M, Parry GCN, Strömblad S, Mackman N, Rosenberg S, Mueller BM, Cheresh DA: Requirement of receptorbound urokinase-type plasminogen activator for integrin $\alpha \mathrm{v} \beta$ 5-directed cell migration. J Biol Chem 271: 29393-29399, 1996

9. Carriero MV, Vecchio SD, Capozzoli M, Franco P, Fontana L, Zannetti A, Botti G, D’Aiuto G, Salvatore M, Stoppelli MP: Urokinase receptor interacts with $\alpha v \beta 5$ vitronectin receptor, promoting urokinase-dependent cell migration in breast cancer. Cancer Res 59: 5307-5314, 1999

10. Band V, Zajchowski D, Swisshelm K, Trask D, Kulesa V, Cohen C, Connolly J, Sager R: Tumor progression in four mammary epithelial cell lines derived from the same patient. Cancer Res 50: 7351-7357, 1990

11. Tuck AB, Wilson SM, Chambers AF: Ras transfection and expression does not induce progression from tumorigenicity to metastatic ability in mouse LTA cells. Clin Exp Metast 8: 417-431, 1990

12. Tuck AB, Wilson SM, Khokha R, Chambers AF: Different patterns of gene expression in ras-resistant and ras-sensitive cells. J Natl Cancer Inst 83: 485-491, 1991

13. Young MF, Kerr JM, Termine JD, Wewer UM, Wang MG, McBride OW, Fisher LW: cDNA cloning, mRNA distribution and heterogeneity, chromosomal location, and RFLP analysis of human osteopontin (OPN). Genomics 7: 491-502, 1990

14. Riccio A, Grimaldi G, Verde P, Sebastio G, Boast S, Blasi F: The human urokinase-plasminogen activator gene and its promoter. Nucl Acids Res 13: 2759-2771, 1985

15. Roldan AL, Cubellis MV, Masucci MT, Behrendt N, Lund LR, Dano K, Appella E, Blasi F: Cloning and expression of the receptor for human urokinase plasminogen activator, a central molecule in cell surface, plasmin dependent proteolysis. EMBO J 9: 467-474, 1990

16. Simon C Juarez J, Nicolson GL, Boyd D: Effect of PD 098059, a specific inhibitor of mitogen-activated protein kinase, on urokinase expression and in vitro invasion. Cancer Res 56: 5369-5374, 1996

17. Xuan JW, Hota C, Shigeyama Y, D'Errico JA, Somerman MJ, Chambers AF: Site-directed mutagenesis of the arginineglycine-aspartic acid sequence in osteopontin destroys cell adhesion and migration functions. J Cell Biochem 57: 680690, 1995

18. Xuan JW, Hota C, Chambers AF: Recombinant GST-human osteopontin fusion protein is functional in RGD-dependent cell adhesion. J Cell Biochem 54: 247-255, 1994

19. Fisher JL, Field CL, Zhou H, Harris TL, Henderson MA, Choong PF: Urokinase plasminogen activator system gene 
expression is increased in human breast carcinoma and its bone metastases - a comparison of normal breast tissue, non-invasive and invasive carcinoma and osseous metastases. Breast Cancer Res Treat 61: 1-12, 2000

20. Senger DR, Perruzzi CA: Cell migration promoted by a potent GRGDS-containing thrombin-cleavage fragment of osteopontin. Biochim Biophys Acta 1314: 13-24, 1996

21. Tuck AB, Elliott BE, Hota C, Tremblay E, Chambers AF: Osteopontin-induced, integrin-dependent migration of human mammary epithelial cells involves activation of the hepatocyte growth factor receptor (Met). J Cell Biochem 78: 465-475, 2000

22. Zohar R, Suzuki N, Suzuki K, Arora P, Glogauer M, McCulloch CA, Sodek J: Intracellular osteopontin is an integral component of the CD44-ERM complex involved in cell migration. J Cell Physiol 184: 118-130, 2000

23. Sung V, Gilles C, Murray A, Clarke R, Aaron AD, Azumi N, Thompson EW: The LCC15-MB human breast cancer cell line expresses osteopontin and exhibits an invasive and metastatic phenotype. Exp Cell Res 241: 273-284, 1998

24. Oates AJ, Barraclough R, Rudland PS: The identification of osteopontin as a metastasis-related gene product in a rodent mammary tumour model. Oncogene 13: 97-104, 1996

25. Chen H, Ke Y, Oates AJ, Barraclough R, Rudland PS: Isolation of and effector for metastasis-inducing DNAs from a human metastatic carcinoma cell line. Oncogene 14: 1581-1588, 1997

26. Hu DD, Lin EC, Kovach NL, Hoyer JR, Smith JW: A biochemical characterization of the binding of osteopontin to integrins alpha v beta 1 and alpha v beta5. J Biol Chem 270: 26232-26238, 1995

27. Liaw L, Skinner MP, Raines EW, Ross R, Cheresh DA, Schwartz SM, Giachelli CM: The adhesive and migratory effects of osteopontin are mediated via distinct cell surface integrins. role of alpha $v$ beta 3 in smooth muscle cell migration to osteopontin in vitro. J Clin Invest 95: 713-724, 1995

28. Smith LL, Cheung HK, Ling LE, Chen J, Sheppard D, Pytela R, Giachelli CM: Osteopontin N-terminal domain contains a cryptic adhesive sequence recognized by alpha9 beta1 integrin. J Biol Chem 271: 28485-28491, 1996

29. Denda S, Reichardt LF, Muller U: Identification of osteopontin as a novel ligand for the integrin alpha 8 betal and potential roles for this integrin-ligand interaction in kidney morphogenesis. Mol Biol Cell 9: 1425-1435, 1998

30. Bayless KJ, Meininger GA, Scholtz JM, Davis GE: Osteopontin is a ligand for the alpha4 beta1 integrin. J Cell Sci 111: 1165-1174, 1998
31. Weber GF, Ashkar S, Glimcher MJ, Cantor H: Receptor-ligand interaction between CD44 and osteopontin (Eta-1). Science 271: 509-512, 1996

32. Bourguignon LY, Gunja-Smith Z, Iida N, Zhu HB, Young LJ, Muller WJ, Cardiff RD: CD44v(3,8-10) is involved in cytoskeleton-mediated tumor cell migration and matrix metalloproteinase (MMP-9) association in metastatic breast cancer cells. J Cell Physiol 176: 206-215, 1998

33. Katagiri YU, Sleeman J, Fujii H, Herrlich P, Hotta H, Tanaka K, Chikuma S, Yagita H, Okumura K, Murakami M, Saiki I, Chambers AF, Uede T: CD44 variants but not CD44s cooperate with beta1-containing integrins to permit cells to bind to osteopontin independently of arginine-glycine-aspartic acid, thereby stimulating cell motility and chemotaxis. Cancer Res 59: 219-226, 1999

34. Jeffers M, Rong S, Vande Woude GF: Enhanced tumorigenicity and invasion-metastasis by hepatocyte growth factor/scatter factor-met signalling in human cells concomitant with induction of the urokinase proteolysis network. Mol Cell Biol 16: 1115-1125, 1996

35. Pepper MS, Matsumoto K, Nakamura T, Orci L, Montesano $\mathrm{R}$ : Hepatocyte growth factor increases urokinase-type plasminogen activator (u-PA) and u-PA receptor expression in Madin-Darby canine kidney epithelial cells. J Biol Chem 267: 20493-20496, 1992

36. Ried S, Jäger C, Jeffers M, Vande Woude GF, Graeff $\mathrm{H}$, Schmitt M, Lengyel E: Activation mechanisms of the urokinase-type plasminogen activator promoter by hepatocyte growth factor/scatter factor. J Biol Chem 274: 16377-16386, 1999

37. Naldini L, Tamagnone L, Vigna E, Sachs M, Hartmann G, Birchmeier W, Daikuhara Y, Tsubouchi H, Blasi F, Comoglio PM: Extracellular proteolytic cleavage by urokinase is required for activation of hepatocyte growth factor/scatter factor. EMBO J 11: 4825-4833, 1992

38. Webb CP, Hose CD, Koochekpour S, Jeffers M, Oskarsson M, Sausville E, Monks A, Vande Woude GF: The geldanamycins are potent inhibitors of the hepatocyte growth factor/scatter factor-met-urokinase plasminogen activator-plasmin proteolytic network. Cancer Res 60: 342-349, 2000

Address for offprints and correspondence: Alan B. Tuck, Department of Pathology, London Health Sciences Centre, Victoria Campus, 375 South St., London, Ontario N6A 4G5, Canada; Tel.: (519) 667-6664 or (519) 685-8651; Fax: (519) 667-6749; E-mail: atuck@julian.uwo.ca 